\title{
The Ameliorating Effects of MSCs in Controlling Treg-mediated B-Cell Depletion by Indoleamine 2, 3-dioxygenase Induction in PBMC of SLE Patients
}

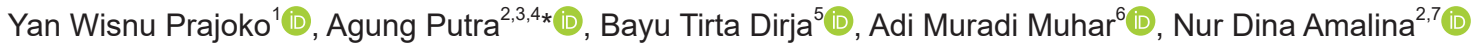 \\ ${ }^{1}$ Department of Surgery, Faculty of Medicine, Universitas Diponegoro, Semarang, Indonesia; ${ }^{2}$ Stem Cell and Cancer Research, \\ Faculty of Medicine, Universitas Islam Sultan Agung, Semarang, Indonesia; ${ }^{3}$ Department of Postgraduate Biomedical Science, \\ Faculty of Medicine, Universitas Islam Sultan Agung, Semarang, Indonesia; ${ }^{4}$ Department of Pathological Anatomy, Faculty of \\ Medicine, Universitas Islam Sultan Agung, Semarang, Indonesia; ${ }^{5}$ Department of Microbiology, Faculty of Medicine, Universitas \\ Mataram, Mataram, Indonesia; ${ }^{6}$ Department of Surgery, Faculty of Medicine, Universitas Sumatera Utara, Medan, Indonesia; \\ ${ }^{7}$ Pharmacy Study Program, Faculty of Mathematics and Natural Sciences, Universitas Negeri Semarang, Semarang, Indonesia
}

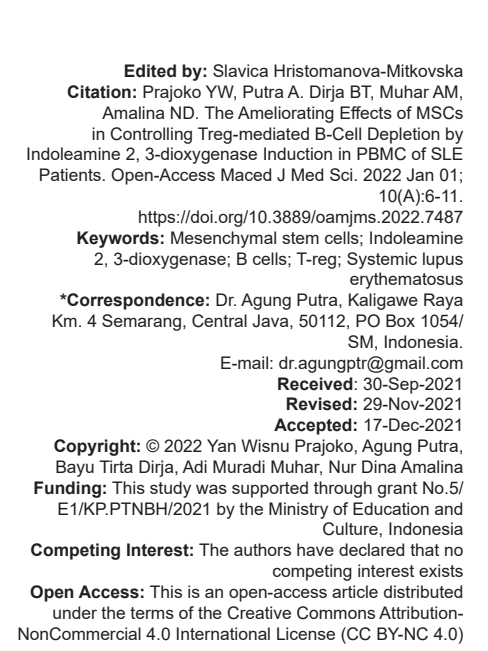

\begin{abstract}
BACKGROUND: Mesenchymal stem cells (MSCs) have potent immunosuppressive properties to control systemic lupus erythematosus (SLE) disease by releasing several anti-inflammatory molecules, particularly indoleamine 2 , 3-dioxygenase (IDO), and increasing regulatory T cells (Treg) to control innate and adaptive immune cells. However, how MSCs release IDO to modulate Treg in controlling B is poorly understood. Therefore, investigating IDO, Treg, and B cells following MSC administration in SLE is needed.
\end{abstract}

AIM: This study aimed to investigate the ameliorating effects of MSCs in controlling B cells mediated by an increase of IDO-induced Treg in PBMC of SLE patients.

METHODS: This study used a post-test control group design. MSCs were obtained from human umbilical cord blood and characterized according to their surface antigen expression and multilineage differentiation capacities. PBMCs isolated from SLE patients were divided into five groups: Sham (placebo group), control, and three treatment groups. The treatment groups were treated by coculturing MSCs to PBMCs with a ratio of 1:10, 1:25, and 1:40 for $72 \mathrm{~h}$ incubation. Treg and B-cell levels were analyzed by flow cytometry with cytometric bead array (CBA) while the IDO levels were determined by ELISA.

RESULTS: This study showed that the percentages of B cells decreased significantly in groups treated by dosedependent MSCs, particularly in T1 and T2 groups followed by increased Treg cell percentages. These findings were aligned with the significant increase of the IDO levels.

CONCLUSIONS: MSCs regulated B cells through an increase of IDO-induced Treg in SLE patients' PBMC.

\section{Introduction}

The systemic lupus erythematosus (SLE) is a complex and heterogeneous systemic autoimmune disease characterized by the presence of pathogenic autoantibodies against a wide variety of nuclear self-antigens, leading to chronic systemic inflammation up to multiple organ damage [1]. The presence of high-affinity autoantibody released by plasma cells (PCs) resulting from $B$ cells terminal differentiation in initiating SLE pathogenesis is well-accepted knowledge [2], [3]. The elevated titer of circular autoantibodies is bound with self-antigen in immunocomplexes formation, then precipitates in certain tissue, leading to chronic inflammation, tissue damage, to organ failure [4], particularly in SLE disease. Thus, suppressing $B$ cells to result in a reduction of PCs to produce autoantibodies have been suggested as the one promising therapy to ameliorate refractory SLE patients. Recent studies reported that mesenchymal stem cells (MSCs) have potent immunosuppressive properties on most immune cells, including T-cell and B-cell lymphocytes [5]. The immunosuppressive effect of MSCs to control the inflammatory milieu, particularly by releasing anti-inflammatory cytokines such as transforming growth factor beta (TGF $\beta)$, IL-10, and indoleamine 2, 3-dioxygenase (IDO) in addition to by modulating regulatory $T$ cells (Treg), has been widely studied [6], [7], [8]. However, the ameliorating effects of MSCs to control B cells in the SLE milieu regarding IDO-induced Treg are still poorly understood. Therefore, investigating B cells and IDO-induced Treg following MSC administration in SLE are needed.

MSCs are multipotent stromal cells that characterized by expression of surface markers including CD73, CD90, CD105, CD44, and CD29, and the lack of expression of typical hematopoietic 
markers including CD45, CD34, CD14, CD11b, CD79a, CD19, and human leukocyte antigen (HLA) Class II. MSCs also show self-renewal and differentiation capacity into different cell lineages under controlled culture conditions [9]. Naturally, the MSCs have been considered as immune-privileged cells due to MSCs exert more potent immunosuppressive effects to mostly immune cells by secreting soluble factors or directly interacting with various effector cells depending on the inflammatory milieu and disease setting [10], [11], in addition low expression of HLA and costimulatory molecules in unstimulated conditions [12]. Given the immunomodulatory properties of MSCs on various immune cells, including lymphocytes, along with their low immunogenic potency, bring these cells about as the one promising new treatment for severe refractory autoimmune diseases, including SLE. Therefore, we focused on exploring the potential of MSCs in SLE patients.

Recent studies reported that MSCs exert more potent immunosuppressive actions on effector T-cell and B-cell proliferation under inflammatory niche either through a cell contact-dependent mechanism such as Tregmodulationorcell contact-independentmechanisms by a release of IDO, PGE2, and cytokines such as TGFb and IL-10 [13]. IDO is a tryptophan degrading enzyme expressed by professional antigen-presenting cells (APCs) to exert important immunosuppressive functions in controlling the inflammatory milieu by inducing the $\mathrm{T}$ regulatory cell proliferation [14]. A previous study reported that MSCs might suppress immunoglobulin production by inhibiting B-cell differentiation into PCs and plasma dendritic cells-induced B-cell maturation under inflammation states [15]. On the other hand, the differentiation of $B$ subsets occurs mainly in response to the T-dependent antigen manner that is influenced by pro-inflammatory cytokines such as type I interferon and IL-6 under the extra-follicular or germinal center pathways [16], [17]. Therefore, it was proposed that the effect of MSCs on B cells is mainly governed by $T$ cell-dependent response rather than direct effects on $B$ cells only, particularly by modulating IDO-induced Treg leading to the improvement of immune response. This study aimed to investigate the ameliorating effects of MSCs in controlling B cells mediated by an increase of IDO-induced Treg in PBMC of SLE patients.

\section{Methods}

\section{Research design}

This study was conducted in Stem Cell and Cancer Research (SCCR) Laboratory, Faculty of Medicine, Sultan Agung Islamic University, Semarang, Indonesia. The design of this study is a post-test control group design. Twenty SLE patients and five healthy subjects were included in this study divided into five study groups, including sham, positive control, and three treatment groups. Subjects were given informed consent for both PBMCs from SLE patients and healthy subjects and cord blood from pregnant donors. This study was approved and in accordance with the Commission on Test Animal Ethics, Faculty of Medicine, Sultan Agung Islamic University (UNISSULA), Semarang, Indonesia, under No. 388/VI/2020/Komisi Bioetik.

\section{MSCs isolation, characterization, and differentiation assay}

MSCs were isolated and separated from cord blood as described previously (Putra et al., 2018) and cultured in Dulbecco's Modified Eagle Medium (Sigma-Aldrich, Louis St, MO) supplemented with $10 \%$ fetal bovine serum (FBS) $\left(\right.$ Gibco $^{\mathrm{TM}}$ Invitrogen, NY, USA), $1 \%$ penicillin $(100 \mathrm{U} / \mathrm{mL}) /$ streptomycin $(100 \mu \mathrm{g} / \mathrm{mL})\left(\right.$ Gibco $^{\mathrm{TM}}$ Invitrogen, NY, USA), and $0.25 \%$ Amphotericin B (Gibco ${ }^{\mathrm{TM}}$ Invitrogen, NY, USA). MSCs were maintained in a humidified atmosphere at $37^{\circ} \mathrm{C}$ and $5 \% \mathrm{CO}_{2}$. The cultured cells medium was replaced every 3 days and passage into new flask culture for further expansion after reached $80 \%$ confluency.

MSCs from the fourth passage were employed for surface antigens characterization. MSCs marker was analyzed by flow cytometry analysis according to company protocols. The fibroblast-like cells were passaged and subsequently stained with allophycocyanin (APC)-, fluorescein isothiocyanate (FITC)-, phycoerythrin (PE)-, and PerCP-Cy5.5.1-mouse anti-human CD73, CD90, Lin (negatively expressed CD34, CD45, CD11b, CD19, and HLA-DR), and CD105 antibodies (562245, BD Biosciences, CA, USA) for $30 \mathrm{~min}$ at room temperature in dark. After stained with a specific antibody, the flow cytometry analysis was performed using BD Accuri C6 Plus flow cytometer (BD Biosciences, CA, USA) and determined using BD Accuri C6 Plus software (BD Biosciences).

The MSCs like from the fourth passage were also expanded to confirm their differentiation into specific differentiated cells. The fibroblast-like cells were cultured in a standard culture medium at $37^{\circ} \mathrm{C}$, $5 \% \mathrm{CO} 2$, and $\geq 95 \%$ humidity. After reaching $95 \%$ confluency, the standard medium was replaced with osteogenic differentiation medium containing Human MesenCult ${ }^{\mathrm{TM}}$ Osteogenic Differentiation Basal Medium (Stem Cell Technologies, Singapore), augmented with 20\% Human MesenCult ${ }^{\mathrm{TM}}$ Osteogenic Differentiation 5X Supplement (Stem Cell Technologies, Singapore) and $1 \%$ L-Glutamine (Gibco ${ }^{\mathrm{TM}}$ Invitrogen, NY, USA) and the cells were incubated at $37^{\circ} \mathrm{C}$ and $5 \% \mathrm{CO}_{2}$. After the appearance of the bone matrix formation, the osteogenic-like cells were washed and incubated with cold $70 \%$ ethanol (v/v) for an hour at room temperature. After the incubation, the cells were rinsed 3 times. 
Alizarin red $(\mathrm{w} / \mathrm{v})(\mathrm{pH} 4.1-4.3)$ was added to perform the calcium deposition on these cells.

\section{Isolation of PBMCs and MSCs coculture}

Human PBMCs were separated from FicollPaque (Sigma-Aldrich, Louis St., MO) density gradient centrifugation in a $15 \mathrm{~mL}$ conical tube from healthy volunteers with informed consent. PBMCs were cultured and expanded in $2 \mathrm{ml}$ of advanced RPMI 1640 culture medium (Gibco ${ }^{\mathrm{TM}}$ Invitrogen, NY, USA), supplemented with $10 \% \mathrm{FBS}, 100 \mathrm{U} / \mathrm{ml}$ penicillin and streptomycin, and $2 \mathrm{mM}$ glutamine, and incubated at $37^{\circ} \mathrm{C}$ in a humidified atmosphere with $5 \% \mathrm{CO}_{2}$. For the treatment group, PBMCs were cocultured with MSCs on T25 flask culture in RPMI supplemented with $1 \%$ penicillin-streptomycin and $10 \%$ FBS at MSCs: PBMCs ratio of 1:10, 1:25, and 1:40 (T1, T2, and T3, respectively) for $72 \mathrm{~h}$. On the other hand, for the sham and control group, the isolated PBMCs $\left(1 \times 10^{7}\right.$ cells/flask $)$ from normal and SLE patients, respectively, were cocultured in the T25 flask with the standard medium for $72 \mathrm{~h}$.

\section{Flow cytometry analysis}

According to the manufacturer's instructions, Treg and B-cell surface markers in the PBMCs population were assessed by flow cytometry analysis after $72 \mathrm{~h}$ of incubation of MSCs. The PBMCs were pelleted by centrifugation at $1900 \mathrm{rpm}$ for $8 \mathrm{~min}$. The supernatant was removed, and pelleted cells were washed using PBS. Approximately $1 \times 10^{5}$ detached cells were resuspended in $100 \mu$ l staining buffer (BD Bioscience, San Jose, CA, USA). For the staining of $B$-cell surface antigens, the cells were subsequently incubated using perCP-conjugated anti-human CD19 (BD Bioscience, San Jose, CA, USA). These cells were incubated for $30 \mathrm{~min}$ at room temperature in the dark. On the other hand, for examining the Treg cells population, the cocultured PBMCs with MSCs were subsequently incubated using FITC- and PE-conjugated anti-human CD4 and CD25, respectively, for $30 \mathrm{~min}$ at room temperature. The cells were then rinsed and incubated using human FoxP3 buffer $\mathrm{A}$ for 10 min and buffer $\mathrm{C}$ for $30 \mathrm{~min}$ for permeabilizing cells. The PBMCs were rinsed again and stained with FoxP3 intracellular antibody for $30 \mathrm{~min}$ at room temperature. In addition, unstained cells were also used to determine a threshold. Each sample was washed twice using PBS, and the analysis was performed using a BD Accuri C6 Plus flow cytometer (BD Bioscience, San Jose, CA, USA). A minimum of $1 \times 10^{4}$ gated events on forward scatter and side scatter were recorded for each sample. The post-acquisition analysis was conducted using the BD Accuri C6 Plus software (BD Bioscience, San Jose, CA, USA).

\section{Determination of IDO level}

The coculture supernatant was collected after $72 \mathrm{~h}$ of incubation. IDO levels were determined in coculture supernatant after $72 \mathrm{~h}$ incubation using specific ELISA. Briefly, according to the manufacturer protocol, the IDO level was analyzed using a standard curve constructed for the specific assay. The absorbance was determined at the wavelength of $450 \mathrm{~nm}$.

\section{Data analysis}

Values were presented as the mean $\pm \mathrm{SD}$. All calculations were carried out using SPSS 16.0 (IBM Corp., Armonk, NY, USA). Group comparisons were analyzed by paired ANOVA and then followed by post hoc Fisher's LSD. $p<0.05$ was considered statistically significant.

\section{Results}

\section{Characteristics of UC-MSCs}

The cell morphology of MSCs at the fourth passage exhibited typical monolayers of spindleshaped fibroblast-like cells, with adhering capability to the plastic flask (Figure 1a). To characterize MSCs surface antigens, we performed flow cytometry analysis as indicated by the International Society for Cellular Therapy. We found a high level of CD90 $(99.7 \pm 2.3 \%)$, CD105 (95.1 $\pm 1.5 \%)$, and CD73 (99.4 $\pm 1.7 \%)$, and low level of CD34, CD45, CD11b, CD19, and HLA-DR, represented as Lin $(0.2 \pm 0.05 \%)$ (Figure $1 b)$.

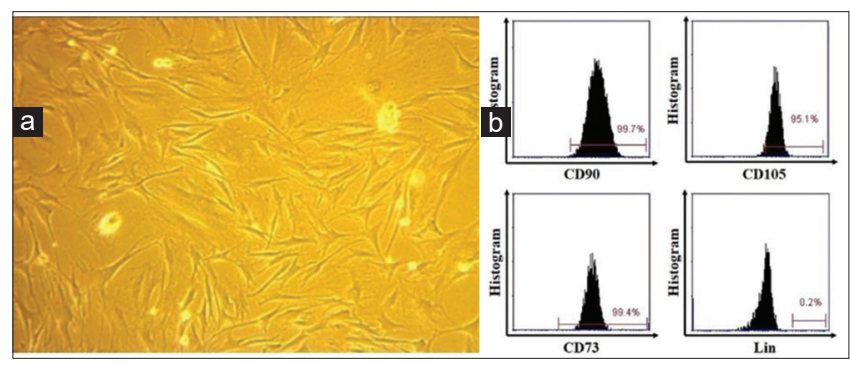

Figure 1: UC-mesenchymal stem cells (MSCs) candidate from the in vitro culture showed spindle form such as fibroblast-like cells (100x) (a), flow cytometry characterization of UC-MSCs expressed $C D 90, C D 105$, and $C D 73$ and negatively expressed CD34, CD45, $C D 11 b, C D 19$, and human leukocyte antigen-DR (b)

\section{In vitro differentiation}

The ability of MSC to differentiate into osteogenic cells was analyzed by culturing the MSCs under an osteogenic medium for 20 days in which the calcium deposition was visualized as red color after alizarin red solution administration. To confirm the in vitro differentiation potential of MSCs, we used an osteogenic differentiation assay to demonstrate the 


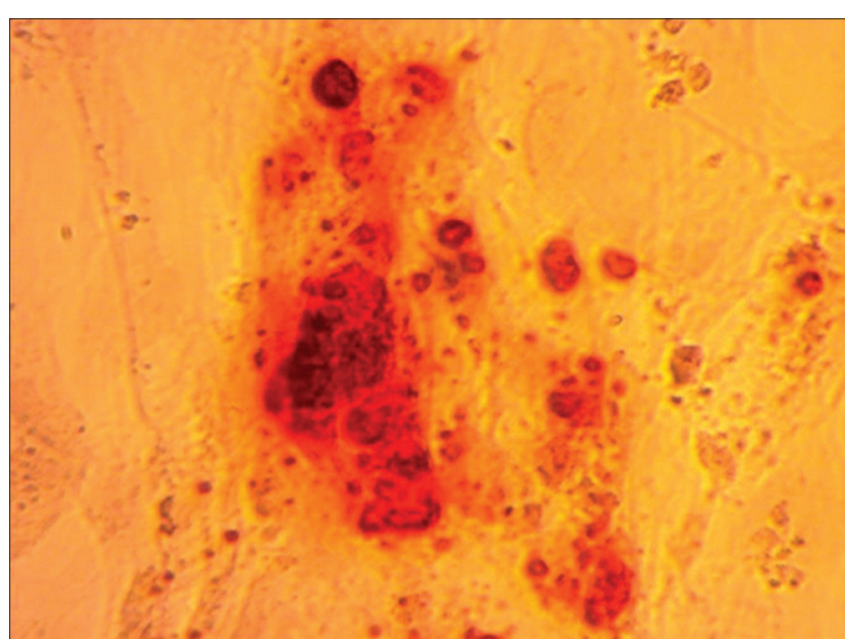

Figure 2: UC-mesenchymal stem cells (MSCs) were treated using an osteogenic differentiation medium to assess the capacity of MSCs to differentiate into the bone matrix. The calcium deposition appeared in red color after alizarin red staining (200x)

ability of MSCs to differentiate into osteogenic cells. Under these osteogenic differentiation assays, we found a red color in most cell cultures as calcium deposition that indicated these MSCs have differentiated into osteogenic (Figure 2).

\section{$T$ cells population \\ MSCs induce functional $C D 4^{+} C D 25^{+}$Foxp $3^{+}$}

A recent study reported that MSCs could represent an alternative therapeutic strategy in refractory SLE patients because of their robust immunosuppressive capacity. MSCs exert anti-inflammatory effects under inflammatory conditions through the induction of a Treg cell phenotype. Our previous study showed that MSCs successfully induce Treg cell phenotype in cocultured MSCs with the PBMCs from SLE patients. However, to investigate the consistency of MSCs in inducing functional Treg cells associated with the decrease of B cells, we cocultured MSCs with PBMCs from SLE patients for $72 \mathrm{~h}$ incubation. In this study, flow cytometry analysis revealed that MSCs increased the percentage of $\mathrm{CD}^{+} \mathrm{CD}^{2} 5^{+} \mathrm{Foxp}^{+} \mathrm{T}$ cells. Furthermore, there was a significant increase of FoxP3 $3^{+}$expression on the $\mathrm{CD}^{+}$ $\mathrm{CD}^{2} 5^{+}$population in all treatment groups $(p<0.001$ and $p<0.05$, respectively), indicated as functional Treg, in which T1 showed the optimum percentage of FoxP3 (80.39 $\pm 8.27 \%$ ) (Figure $3 a$ and b).

\section{MSCs decrease B-cell population in the cocultured PBMCs}

MSCs could robustly inhibit the excessive inflammatory milieu established by the autoreactive immune cells, particularly the autoreactive B cells. However, B-cell emergence as one of the major factors responsible for autoantibody-produced PC production remains to be further elucidated.

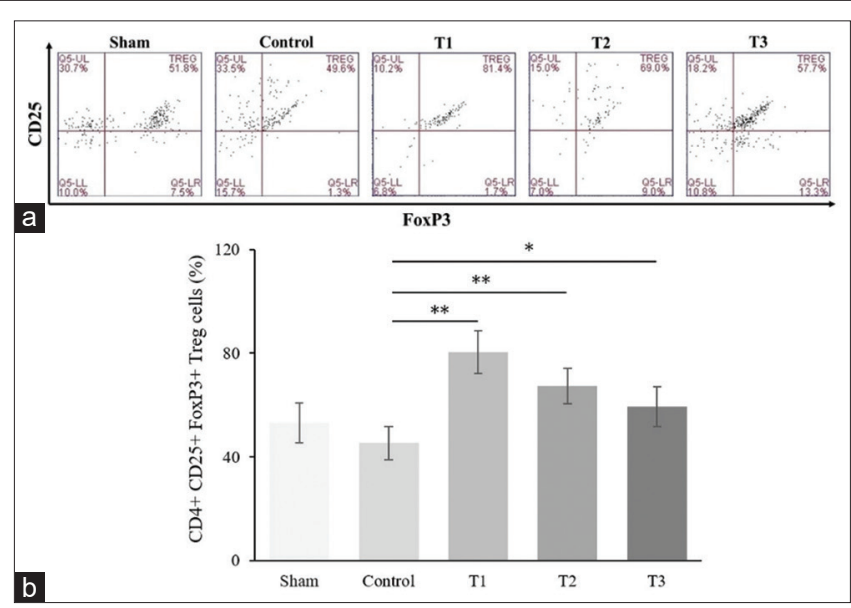

Figure 3: (a) Flow cytometry analysis showed that mesenchymal stem cells induce Treg cells. The analysis was defined as $C D 4^{+} C D 25^{+} F_{0 x P 3^{+}}$. (b) Quantification of Treg cells was repeated three $\left({ }^{*} p<0.05\right.$ and $\left.{ }^{* *} p<0.001\right)$

Therefore, to investigate the capacity of MSCs in inhibiting B cells in vitro, we cocultured MSCs with PBMCs from SLE patients for $72 \mathrm{~h}$ incubation and analyzed the CD19 as one of the novel markers in $B$ cells using flow cytometry (Figure 4a). This study that MSCs could inhibit the percentage of B cells population in which there was a significant decrease of CD19 population in the PBMCs population in the T1 and T2 groups $(p<0.05)$, in which the percentage of CD19 in T1 was $1.70 \pm 0.15 \%$ and in T2 was $1.9 \pm$ $0.59 \%$ (Figure 4b).

\section{MSCs enhance the IDO levels in the coculture between MSCs and SLE PBMCs}

To investigate the capacity of MSCs in enhancing the level of IDO, the ELISA assay was performed after 72 of $h$ incubation of MSCs and PBMCs coculture. The ELISA assay showed that there was a significant increase of IDO in all treatment groups, compared with the control group ( $p<0.001$ and $p<0.05$; respectively), in which T1 showed the highest IDO level $(230.76 \pm 8.61 \mathrm{pg} / \mathrm{mL})$ (Figure 5).

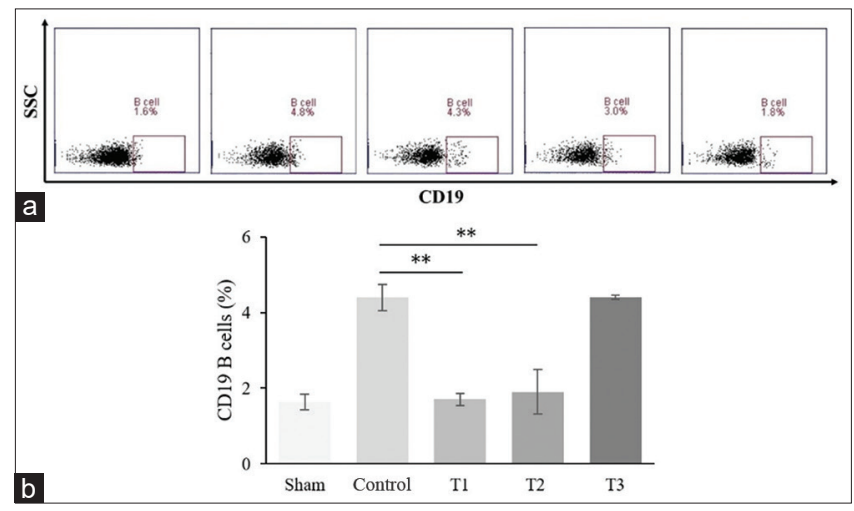

Figure 4: (a) Mesenchymal stem cells inhibit B-cell generation in SLE PBMCs. Flow cytometry is used to identify B cells. (b) Quantification of $B$ cells was repeated 3 times $(* * p<0.001)$ 


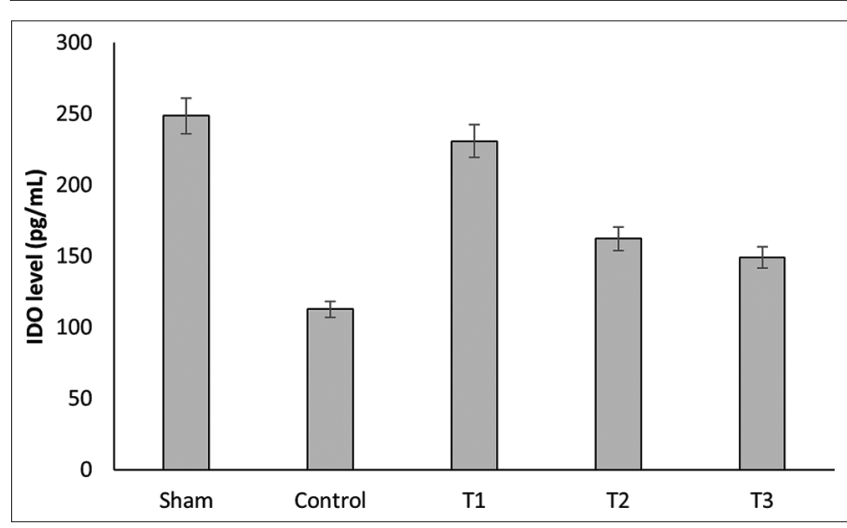

Figure 5: Mesenchymal stem cells (MSCs) enhance indoleamine 2, 3-dioxygenase level in the coculture between MSCs and SLE PBMCs in vitro $(* p<0.05 ; * * p<0.001)$

\section{Discussion}

MSCs have recently provided new insights for clinical use in controlling autoimmune diseases, including SLE. One prominent immunosuppressive property of MSCs against autoreactive lymphocytes in SLE disease is their ability to generate functional Treg cells, known as iTreg. Our previous study showed that MSCs also modulated several effector immune functions to control the inflammatory milieu in SLE by enhancing CD4, CD25, and Fox-3 lymphocytes capacities as a functional Treg [7], [8]. However, the ameliorating effects of MSCs on B cells and PCs in SLE are still poorly understood. Moreover, the role of MSCs to control the inflammatory milieu triggered by PC producing autoantibodies as the terminal differentiation of $B$ cells involving IDO-induced Treg also remains undetermined [18]. To investigate the MSCs to B cells by modulating IDO-induced Treg to result in the normal PCs in producing antibodies, we isolated PBMC from SLE patients to treat with MSCs in vitro. We then analyzed the number of Treg, $B$ cells, and IDO as the crucial point in addressing one of the SLE pathogeneses.

Our previous study reported that MSCs could ameliorate SLE disease, by modulating inducible Treg (iTreg) cells through the regulation of TGF- $\beta$. However, the effect of MSCs on B cells and PCs regarding Treg and IDO is still poorly understood. This study demonstrated that MSCs could suppress the B cells in SLE patients by increasing IDO with Treg levels. These effects were dose dependent, and an increase in the ratio of the doses of MSCs to PBMCs (from 1:10 to 1:25) resulted in a $25-30 \%$ decrease in B cells. These findings were in line with the increase of Treg levels in a similar ratio of those MSC to B cells, indicating any correlation between the decrease of $B$ cells and the increase of Treg cells following MSCs administration. The ability of MSCs to modulate Treg is consistent with our previous findings that demonstrated MSCs modulated i-Treg in cocultured with the PBMC of SLE patients [7], [8]. Whereas the Treg capacities to suppress B cells in SLE are supported by another study that Treg can inhibit B cells when the Treg was cocultured Treg together with $\mathrm{CD}^{-19^{+} \mathrm{CD} 27^{-} \mathrm{lgD}}$ $\mathrm{B}$ cells or autologous $\mathrm{CD} 19^{+} \mathrm{CD} 27^{\text {high }}$ high $\mathrm{B}$ cells, as the cells producing the serologic abnormalities in SLE patients with active lupus [19].

Interestingly, this study found the increase of IDO in line with the ratio of the doses of MSCs to iTreg cells. IDO enzymatically degrades tryptophan resulting in an accumulation of downstream breakdown products of kynurenine to exhibit biological activity in the immune system, including by inducing Treg function through as a signaling protein shapes the immunological microenvironment. This is in line with a previous study that reported IDO might control the inflammatory milieu by inducing $\mathrm{i}$-Treg cells [20]. Under the suppression of $B$ cells by i-Treg following MSCs administration, the B-cell cycle was arrested in $G 0 / G 1$, leading to the inhibition of their differentiation into PCs and subsequent Ig formation [21], [22]. These findings suggested that MSCs could control B cells by increase IDO-induced Treg, resulting in a reduction of autoantibodies release leading to ameliorate the effect of SLE disease. However, in this study, we did not coculture the MSC with the isolated B cells, and the isolated Treg and analyze the differentiated PCs, in this SLE, therefore, the detailed mechanism of how MSCs to control B cells by increase of IDO-induced Treg in PBMC of SLE patients could not be explained yet.

\section{Conclusions}

The ministry of Education and Culture, Indonesia, grant of basic research of higher education No.5/E1/KP.PTNBH/2021 and the Stem Cell and Cancer Research (SCCR) Laboratory, the medical faculty at Sultan Agung Islamic University, Semarang, Indonesia and all who contributed to this research.

\section{Acknowledgment}

The Ministry of Education and Culture, Indonesia, grant of basic research of higher education No.5/E1/KP.PTNBH/2021 and the Stem Cell and Cancer Research (SCCR) Laboratory, the medical faculty at Sultan Agung Islamic University, Semarang, Indonesia and all who contributed to this research.

\section{Authors' Contributions}

The authors confirm contribution to the paper as follows, YWP and AP: Study conception and design. 
BTD, YWP, and NDA: Performed experiments, analyzed data, and cowrote the paper. AMM and AP: Supervised the research and wrote the paper.

\section{References}

1. Yaniv G, Twig G, Shor DB, Furer A, Sherer Y, Mozes O, et al. A volcanic explosion of autoantibodies in systemic lupus erythematosus: A diversity of 180 different antibodies found in SLE patients. Autoimmun Rev. 2015;14(1):75-9. https://doi. org/10.1016/j.autrev.2014.10.003

PMid:25449682

2. Malkiel S, Barlev AN, Atisha-Fregoso $\mathrm{Y}$, Suurmond J, Diamond B. Plasma cell differentiation pathways in systemic lupus erythematosus. Front Immunol. 2018;9:427. https://doi. org/10.3389/fimmu.2018.00427

PMid:29556239

3. Yap DY, Chan TM. B cell abnormalities in systemic lupus erythematosus and lupus nephritis-role in pathogenesis and effect of immunosuppressive treatments. Int J Mol Sci. 2019;20(24):6231. https://doi.org/10.3390/ijms20246231 PMid:31835612

4. Prechl J. A generalized quantitative antibody homeostasis model: Antigen saturation, natural antibodies and a quantitative antibody network. Clin TransI Immunol. 2017;6(2):e131. https:// doi.org/10.1038/cti.2016.90

PMid:28496977

5. Barbado J, Tabera S, Sánchez A, García-Sancho J. Therapeutic potential of allogeneic mesenchymal stromal cells transplantation for lupus nephritis. Lupus. 2018;27(13):2161-5. https://doi.org/10.1177/0961203318804922

PMid:30290717

6. Putra A, Ridwan FB, Putridewi Al, Kustiyah AR, Wirastuti K, Sadyah NA, et al. The role of TNF- $\alpha$ induced MSCs on suppressive inflammation by increasing TGF- $\beta$ and IL-10. Open Access Maced J Med Sci. 2018;6(10):1779-83. https:// doi.org/10.3889/oamjms.2018.404

PMid:30455748

7. Darlan DM, Munir D, Putra A, Jusuf NK. MSCs-released TGF $\beta 1$ generate CD4+CD25+Foxp3+ in T-reg cells of human SLE PBMC. J Formos Med Assoc. 2020;120(1):602-8. https://doi. org/10.1016/j.jma.2020.06.028

PMid:32718891

8. Ikhsan R, Putra A, Munir D, Darlan DM, Suntoko B, Kustiyah AR, et al. Mesenchymal stem cells induce regulatory T-cell population in human SLE. BJMS. 2020;19(4):743-8.

9. Baghaei K, Hashemi SM, Tokhanbigli S, Asadi Rad A, Assadzadeh-Aghdaei $\mathrm{H}$, Sharifian A, et al. Isolation, differentiation, and characterization of mesenchymal stem cells from human bone marrow. Gastroenterol Hepatol Bed Bench. 2017;10(3):208-13. PMid:29118937

10. Gebler A, Zabel O, Seliger B. The immunomodulatory capacity of mesenchymal stem cells. Trends Mol Med. 2012;18(2):128-34. https://doi.org/10.1016/j.molmed.2011.10.004

PMid:22118960

11. Crop MJ, Baan CC, Korevaar SS, ljzermans JN, Pescatori M,
Stubbs AP, et al. Inflammatory conditions affect gene expression and function of human adipose tissue-derived mesenchymal stem cells. Clin Exp Immunol. 2010;162(3):474-86. https://doi. org/10.1111/j.1365-2249.2010.04256.x

PMid:20846162

12. Dorraji SE, Hovd AK, Kanapathippillai P, Bakland G Eilertsen $G \varnothing$, Figenschau SL, et al. Mesenchymal stem cells and $T$ cells in the formation of tertiary lymphoid structures in lupus nephritis. Sci Rep. 2018;8(1):7861. https://doi.org/10.1038/ s41598-018-26265-z

PMid:29777158

13. Haddad R, Saldanha-Araujo F. Mechanisms of T-cel immunosuppression by mesenchymal stromal cells: What do we know so far? Biomed Res Int. 2014;2014:216806. https:// doi.org/10.1155/2014/216806 PMid:25025040

14. Wu H, Gong J, Liu Y. Indoleamine 2, 3-dioxygenase regulation of immune response (Review). Mol Med Rep. 2018;17(4):4867-73. https://doi.org/10.3892/mmr.2018.8537 PMid:29393500

15. Comoli P, Ginevri F, Maccario R, Avanzini MA, Marconi M, Groff A, et al. Human mesenchymal stem cells inhibit antibody production induced in vitro by allostimulation. Nephrol Dial Transplant. 2008;23(4):1196-202. https://doi.org/10.1093/ndt/ gfm740 PMid: 18029377

16. Shih TA, Roederer M, Nussenzweig MC. Role of antigen receptor affinity in $\mathrm{T}$ cell-independent antibody responses in vivo. Nat Immunol. 2002;3(4):399-406. https://doi.org/10.1038/ni776 PMid:11896394

17. Lentz VM, Manser T. Cutting edge: Germinal centers can be induced in the absence of T cells. J Immunol. 2001;167(1):1520. https://doi.org/10.4049/jimmunol.167.1.15

PMid: 11418626

18. Chappell CP, Draves KE, Giltiay NV, Clark EA. Extrafollicular B cell activation by marginal zone dendritic cells drives T cell-dependent antibody responses. J Exp Med. 2012;209(10):1825-40. https://doi.org/10.1084/jem.20120774 PMid:22966002

19. likuni N, Lourenço EV, Hahn BH, La Cava A. Cutting edge: Regulatory $T$ cells directly suppress $B$ cells in systemic lupus erythematosus. J Immunol. 2009;183(3):1518-22. https://doi. org/10.4049/jimmunol.0901163

PMid:19570829

20. Danikowski KM, Jayaraman S, Prabhakar BS. Regulatory $\mathrm{T}$ cells in multiple sclerosis and myasthenia gravis. J Neuroinflammation. 2017;14(1):117. https://doi.org/10.1186/ s12974-017-0892-8

PMid:28599652

21. Corcione A, Benvenuto F, Ferretti E, Giunti D, Cappiello V Cazzanti $F$, et al. Human mesenchymal stem cells modulate B-cell functions. Blood. 2006;107(1):367-72. https://doi. org/10.1182/blood-2005-07-2657

PMid: 16141348

22. TaberaS, Pérez-Simón JA, Díez-Campelo M, Sánchez-Abarca LI, Blanco B, López A, et al. The effect of mesenchymal stem cells on the viability, proliferation and differentiation of B-lymphocytes. Haematologica. 2008;93(9):1301-9. https://doi.org/10.3324/ haematol.12857

PMid:18641017 